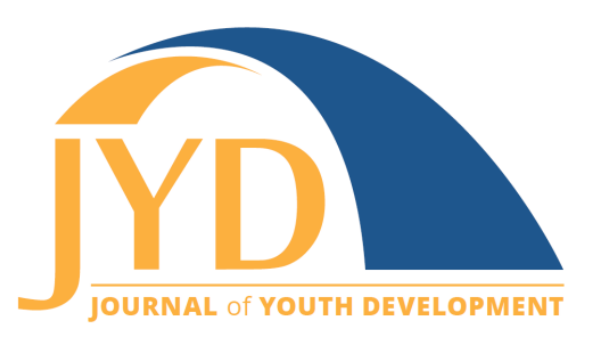

http://jyd.pitt.edu/ | Vol. 16 Issue 5 DOI 10.5195/jyd.2021.1084 | ISSN 2325-4017 (online)

\title{
Increasing Latinx Youth Engagement Across Different Types of After-School Organizations
}

\author{
Fe Moncloa \\ University of California, Agriculture and Natural Resources \\ fxmoncloa@ucanr.edu \\ Nancy Erbstein \\ University of California, Davis \\ nerbstein@ucdavis.edu \\ Aarti Subramaniam \\ University of California, Agriculture and Natural Resources \\ asubramaniam@ucdavis.edu
}

\begin{abstract}
This article explores how Latinx youth engagement practices vary across different types of out-of-school organizations that successfully sustain Latinx youth participation. Data are drawn from a qualitative study of 13 California organizations that each emphasize one of 3 missions: social justice youth development, "one-stop" wrap-around services, or academic enrichment. While all organizations are found to adhere to a core set of Latinx youth development guiding principles, there are nuanced differences in how they are operationalized in practice across varied organization types, reflecting variation in terms of discourse, scale, and scope. These findings highlight the need for youth development practitioners and collaborating researchers to understand the context of youth-serving organizations when identifying and implementing promising practices and extension programs.
\end{abstract}

Key words: Latinx youth development, out-of-school organizations

\section{Introduction}

The Latinx population is the second-fastest-growing ethnic group in the United States after Asian Americans; it is also the youngest ethnic group. California has the largest Latinx population under 18 years of age among all states in the United States (Pew Research Center, 2014). Historically, Latinx youth faced structural inadequacies of policies and public institutions which did not address the unique needs of Latinx youth and their families (Gandara \&

(cc) EY New articles in this journal are licensed under a Creative Commons Attribution 4.0 License. This journal is published by the University Library System, University of Pittsburgh and is cosponsored by the University of Pittsburgh Press. The Journal of Youth Development is the official peer-reviewed publication of the National Association of Extension 4-H Youth Development Professionals and the National AfterSchool Association. 


\section{Increasing Latinx Youth Engagement}

Contreras, 2009; Rodriguez \& Morrobel, 2004). This context suggests the importance of understanding how youth development organizations engage Latinx youth well and develop strategies to support Latinx youth and community development. In response, this study is grounded in the imperative that academic researchers partner with youth-serving institutions that successfully reach and sustain the participation of our most underserved populations to articulate and disseminate nuanced understandings of "what works" to inform praxes. In this article we explore how Latinx youth engagement practices vary across different types of out-ofschool organizations that sustain Latinx youth participation (Erbstein \& Fabionar, 2019). We examine organizations that emphasize one of three missions: social justice youth development, "one-stop" wrap-around services, and academic enrichment.

\section{Review of the Literature}

Erbstein and Fabionar (2019) conducted a review of Latinx youth development scholarship and practice-based literature from the fields of ethnic studies, sociology, anthropology, youth studies, and human development, which revealed five consistent themes that exist in successful Latinx youth serving organization. These themes, presented as guiding principles suggested organizations (a) contend with effects of discrimination, (b) respond to poverty, (c) address local youth needs, (d) provide support for ethnic or other identity, and (e) have an integrated understanding of youth development. They have implications for all four domains of youth development organizations: conceptual framework, organizational infrastructure, program elements, and program and community relationships (Eccles \& Gootman, 2002). This line of inquiry provides little guidance on the types of youth development organizations that engage and support Latinx youth well.

Few scholars describe the types of youth-serving organizations that engage vulnerable youth. For example, Wheeler (2000) examined similar national youth-serving organizations to identify their salient characteristics and McLaughlin et al., (2009) examined community-based urban organizations that advocate for youth or organizations helping community members engage in advocacy themselves. To our knowledge, the literature does not currently describe the different types of youth development organizations, nor does it include how these types of youth development organizations sustain Latinx youth participation.

Most scholars describe the characteristics of youth development program types (Catalano et al., 2002; Eccles \& Templeton, 2002; Futch Ehrlich et al., 2017; Mahoney et al., 2009). We rely on the following youth development program descriptions during out-of-school time to inform our study: 


\section{Increasing Latinx Youth Engagement}

- After-school enrichment programs offer experiential learning activities on a regular basis throughout the school year and are supervised by adults with opportunities of peer mentoring. Youth have choices from a variety of group activities and engage in peer interaction (Mahoney et al., 2006). Summer camps are similarly organized and offer day or overnight activities.

- Civic engagement programs address organizational or community change on a regular basis and may be youth-led or led by a youth-adult partnership (Zeldin et al., 2014). Activities include youth advisory boards (Hohenemser \& Marshal, 2002), youth participatory action research (Cammarota \& Fine, 2008; Kirshner et al., 2011; Fox et al., 2010), or social justice youth development (SJYD) (Ginwright \& Cammarota, 2007). SJYD programs build marginalized youth's critical consciousness (Horton \& Freire, 1990); increase youth's understanding of inequitable systems; and strengthen their capacity to transform these systems through collective action (Ginwright \& Cammarota, 2007) to "convince, pressure, or coerce external decision-makers to modify or stop certain activities" (Staples, 2004, p.9). SJYD programs focus on youth's identity development and embrace youth culture (Erbstein, 2013).

- Comprehensive family support organizations (one-stop) provide youth- and familyfocused services for prevention or crisis intervention. Organizations engage marginalized youth and family members to address current and emerging multidimensional issues of families and communities (Trask et al., 2006; Settipani et al., 2019.

Building on Erbstein and Fabionar's (2019) strategies for Latinx youth engagement in quality out-of-school time programs, an empirical study of 13 California organizations that successfully sustain Latinx youth participation confirmed the importance of these principles, identified similarities among organizations, and described practices from practitioners and youth perspectives that operationalized them (Moncloa et al. 2019). These Latinx youth organizations illustrated the importance of including equitable access in organizations' conceptual framework, providing equitable programs and accessible locations as imperative elements to consider, employing staff at all organizational levels who reflect the demographics and shared experiences of youth served, creating culturally relevant learning environments informed by local context and lived experiences of youth and families, and supporting young people to navigate discrimination and negative messaging. However, among these organizations there were differences in how they framed their conceptual frameworks, missions, and programs. Effective Latinx youth development organizations use a guiding philosophy that builds on mainstream positive youth development research and practice (Gambone \& Connell, 2004; Lerner et al., 2011) and include an emphasis on extended understandings of Latinx youth 
development (Erbstein \& Fabionar, 2019; Moncloa et al., 2019). In this article, we explore whether there is substantive variation in how different youth development organization types operationalize these guiding principles.

\section{Methods}

\section{Sample}

This 2-year qualitative study was conducted from 2016-2018 and draws upon interviews with 18 youth-serving professionals representing 13 Latinx youth development organizations in three California counties (Moncloa et al., 2019). Organizations were selected through a process of mapping the ecosystem of Latinx youth supports in each county, organizational research, and key informant interviews (Erbstein et al., 2017). These organizations had engaged Latinx youth for at least 1 year, sustained most Latinx youth participation, and were broadly known to have a positive reputation among Latinx youth, families, and communities in their regions.

\section{Procedures}

Data collection included organizational documents reflecting their missions, activities, and inperson semi-structured interviews with organizational leaders and staff members who worked with youth. We include interviewees' country or region of origin to reflect how people selfidentified in Table 1. The University of California Davis Institutional Review Board approved data collection protocols.

\section{Table 1. Staff Interviewee Demographics}

\begin{tabular}{|l|l|}
\hline Demographic & \multicolumn{1}{|c|}{ Characteristics } \\
\hline Ethnicity & $\begin{array}{l}\text { Latinx from Mexico (15) Mixteco (1) } \\
\text { Latinx-Asian (1) } \\
\text { Latinx from Guatemala (1) }\end{array}$ \\
\hline Gender & $\begin{array}{l}\text { Female (9) } \\
\text { Male (9) }\end{array}$ \\
\hline Age range & Early 20s to late 30s \\
\hline
\end{tabular}

Interviews elicited practitioners' perspectives on their backgrounds, and their strategies to recruit and sustain Latinx youth participation in youth development organizations and programs. The protocol included open-ended questions regarding organizations' goals, missions, history, and stories about successes and challenges. All interviews were conducted in English, although 
Journal of Youth Development | http://jyd.pitt.edu/ | Vol. 16 Issue 5 DOI 10.5195/jyd.2021.1084

Increasing Latinx Youth Engagement

participants often employed some Spanish. Interviews were digitally recorded and transcribed verbatim in both languages.

\section{Analysis}

To identify variations among three organization types, data was grouped together as cases as described in Table 2, where the unit of analysis is the organization type (Yin, 2009).

Table 2. Organization Location, Type, and Staffing and Participant Data

\begin{tabular}{|c|c|c|c|c|}
\hline County & $\begin{array}{c}\text { Organization name } \\
\text { (Pseudonym) }\end{array}$ & No. of staff & $\begin{array}{l}\text { Annual youth } \\
\text { participants }\end{array}$ & Organization type \\
\hline Merced & Just Media & 5 & $\begin{array}{c}45 \text { teens/college } \\
\text { aged }\end{array}$ & Social justice/Advocacy \\
\hline Santa Clara & Social Justice Advocates & 5 & 20 teens & Social justice/Advocacy \\
\hline Riverside & Wellness in Community & 1 & 200 teens & Social justice/Advocacy \\
\hline Riverside & Design Your City & 2 & 20 teens & Social justice/Advocacy \\
\hline Riverside & Building Cultural Identity & 15 volunteers & 60 teens & Social justice/Advocacy \\
\hline Santa Clara & Comprehensive Support & 8 & $\begin{array}{c}200 \text { children and } \\
\text { teens }\end{array}$ & Social justice and One-stop \\
\hline Santa Clara & Urban Art Promotion & 4 & 15 teens & Enrichment \\
\hline Santa Clara & $\begin{array}{l}\text { Youth and Family } \\
\text { Community Center }\end{array}$ & $\begin{array}{l}6 \text { staff \& } 4 \\
\text { volunteers }\end{array}$ & 200 children & Enrichment \\
\hline Santa Clara & Youth Afterschool & 29 & 8,500 children & Enrichment \\
\hline Riverside & Mentoring Youth of Color & 1 & 250 children & Enrichment \\
\hline Riverside & Expanded Learning for All & $\begin{array}{c}364 \text { staff \& } \\
1,700 \\
\text { volunteers }\end{array}$ & 36,000 children & Enrichment \\
\hline Merced & Pueblos Indigenas & 2 & 20 teens & Enrichment and One-stop \\
\hline Merced & United for Youth & 8 & 20 teens & Enrichment and One-stop \\
\hline
\end{tabular}

We used grounded analysis (Charmaz, 2006; Strauss \& Corbin, 1998) and NVIVO 11 to conduct queries of previously coded interviews to identify how the guiding principles varied across organization types. Queries revealed salient practices in three organization types and identified quantity and quality of practices with respect to organizations'(a) conceptual frameworks, (b) organization infrastructure, (c) program elements, and (d) community relationships (Eccles \& Gootman, 2002). Quantity refers to the number of times interviewees mentioned a certain 
concept or approach, while quality indicates variations in the operationalization of the approach. Guiding principles and practices that were operationalized in varied ways across organizational categories were further considered to assess the nature of these differences and potential explanatory factors. Table 3 describes in detail the data analysis process.

Table 3. Data Analysis Process

\begin{tabular}{|c|c|}
\hline Data analysis process & Description \\
\hline $\begin{array}{l}\text { Queries: Variations among } \\
\text { organizations }\end{array}$ & $\begin{array}{l}\text { Explored previously coded interviews using queries in NVIVO } 11 \\
\text { to examine variations in practices by organization type. Focused } \\
\text { on adult perspectives. }\end{array}$ \\
\hline Coding refinement & $\begin{array}{l}\text { Pursued a grounded analysis (Strauss \& Corbin, 1998; Charmaz, } \\
\text { 2006) to refine coding based on whether and how organization } \\
\text { types varied across the guiding principles: (a) support ethnic } \\
\text { and other identity development; (b) tailor efforts to individual } \\
\text { and family needs; (c) contend with discrimination; (d) address } \\
\text { poverty; (e) had an integrated approach to youth development. } \\
\text { Integrated this analysis with respect to organizations' (a) } \\
\text { conceptual frameworks, (b) organization infrastructure, (c) } \\
\text { program elements, and (d) community relationships. }\end{array}$ \\
\hline $\begin{array}{l}\text { Potential variation } \\
\text { identification }\end{array}$ & $\begin{array}{l}\text { Identified potential variations on key practices based on the } \\
\text { magnitude of nodes (number of organization types where a } \\
\text { practice featured), as well as prominence of the concept (how } \\
\text { much it was described or articulated). }\end{array}$ \\
\hline Key practices confirmation & $\begin{array}{l}\text { In the description of organization types, we do not attribute } \\
\text { specific counts of the number of interviewees who mentioned a } \\
\text { particular theme. Identified practices pursued by at least three } \\
\text { organizations were identified as themes. Reviewed original } \\
\text { transcripts and field notes to check findings. Each practice was } \\
\text { discussed and agreed upon by full team. Analytical memos were } \\
\text { coded and analyzed. }\end{array}$ \\
\hline Salient quote identification & $\begin{array}{l}\text { Salient quotes were placed in an Excel sheet to identify } \\
\text { variations among organization types and to facilitate the } \\
\text { constant comparative analysis. }\end{array}$ \\
\hline
\end{tabular}




\section{Positionality}

Field researchers resided in regions where they conducted interviews. All except one, of White European descent, were Latinx native Spanish speakers. Two authors are Latinx or Indian immigrants, and one author is of White European descent; the former are researchers and youth development practitioners, and the latter, while formerly a youth development practitioner, is now based in academia.

\section{Findings}

Data analysis revealed differences with respect to conceptual frameworks and program elements, which were associated with organization type. Conceptual frameworks include organizations' missions and philosophy that inform practice. Program elements include safe learning environment, positive relationships, social norms, skill building, youth leadership, and topical emphasis (Eccles \& Gootman, 2002).

\section{Social Justice Youth Development and Advocacy Organizations}

Social Justice Youth Development and Advocacy organizations' (SJYD) missions aim to facilitate healthy development of young people-especially those marginalized based on race/ethnicity, socioeconomic status, or other characteristics-to develop an understanding of systems that produced inequitable structures of opportunity and outcomes, as well as the capacity to change them. Their missions include helping youth develop critical consciousness and language to articulate structural and cultural barriers experienced by their communities, along with the agency to begin contesting these by tapping community strengths. A staff member from Building Cultural Identity shares:
A lot of our students now . . . are able to understand our conditions in our community from a very critical lens. They can understand it from race, class, gender . . . they built their skill sets to be able to understand our community as more than just . . . the east side is poor because that's how you lived, right? They have the understanding that we live in communities that are a result of these systems.

In these organizations, staff reported Latinx youth learned to express themselves against injustice in their communities, work on art installations to highlight their culture, and facilitated activities to promote community building.

In all organizations, staff members share similar cultural backgrounds, language(s), and lived experiences with participating youth (Moncloa et al., 2019). In SJYD organizations staff draw on 


\section{Increasing Latinx Youth Engagement}

their personal journeys to help youth transcend and transform daily microaggressions and structural barriers. Staff support youth's ethnic identity development as a foundation for social transformation efforts. Staff from Building Cultural Identity state:

We talk about just different issues: what it means to be a woman of color here in the valley, here in this country, what are some of the things that we face, and how do we deal with those things. How do we put ourselves in situations where we-in spaces where we feel we don't belong. For example, you know, college, university, certain classes, certain jobs, certain environments and, you know, we cannot just feed off of each other. And what are the different things that wethe micro-aggressions that we face every day, and sort of putting a name to something that we've always felt.

In SJYD, few organizations used curriculum. A staff member from Wellness in Community states:

I make sure that their opinions are input, and their work is actually what moves whatever we're doing forward. Rather than I'm moving it forward and I'm trying to drag them along. I really make sure that every day we emphasize every time we meet that we're gonna go as far as the whole group wants us to go. And it's gonna look the way the group wants it to look like.

Staff develop relationships with youth that often extend beyond program participation. A staff member from Just Media revealed how program scope extends beyond regular work hours:

When youth get triggered and are encountering racism in the community, like it's not during your regular office hours. These are experiences that you share all times. Like we are in our homes, we experience sexism or misogyny, all these things.

SJYD engage with youth beyond youth's participation in organizations. A staff member describes a longer time horizon to support youth to achieve change:

After Just Media they will try to go out there and achieve it because they know Just Media is always going to be here. And no matter what, we'll always be here to back each other up. And when something goes wrong, we're always here to help. So, it's like no matter what, we're always going to be a family.

\section{One-Stop Organizations}

One-stop organizations' missions centered on providing services and programs with and for youth, families, and communities. Within our sample, these organizations in some cases also 
embodied goals similar to SJYD or enrichment. For example, Comprehensive Support sought to alleviate effects of poverty via service provision and their primary practices include an out-ofschool program for pre- $K$ through eighth-grade youth, parent education classes, free food and clothing, and legal services. Their staff describe supporting family engagement in community advocacy with respect to immigrant rights. A staff member from Comprehensive Support states their policy and organizing team support immigrant families and "continue that work around immigration. And really right now, we're just focusing on, know-your-rights campaigns."

In all organizations, staff build trust and familiarity with families and youth they aim to engage (Moncloa et al., 2019). One-stop organizations with a SJYD focus engage their families in decision making and were adept at providing a variety of resources based on family needs. For example, Comprehensive Support helps families with house rents, weatherization, or facilitating garden plot access. This intentional family engagement set them apart from academic enrichment and SJYD organizations.

Similar to SJYD, staff at one-stop organizations cultivate young people's healthy ethnic identity development. However, one-stop organizations whose mission includes enrichment programs focus on establishing a connection between youth and their culture to build knowledge and pride, rather than tapping identity as a foundation for social transformation efforts. A staff member from Pueblos Indigenas states:

Working with these young people for the last six years, where [there is] one workshop where they learn about what is it to be Mixteco, what is the background of Mixteco, and how was our civilization before. They continue coming back because that's the work that we do. And every time that we conduct a workshop or even young people interested in the folkloric dances, that really focuses on that, a place where we [are] coming from, participating in the yearly event, cultural event that we have where the best food of our community, dances, and music come all together once a year.

\section{Enrichment Organizations}

Enrichment organizations' mission is to provide a range of educational activities-including arts, science, homework tutoring, and college and career access-to improve competencies and academics of youth in Grades K-8. In most organizations staff select activities for children in elementary and middle school grades. In Urban Art Promotion, an organization that engaged adolescents, youth selected their activities. 


\section{Increasing Latinx Youth Engagement}

Staff in all enrichment organizations are familiar with the local community and make efforts to get to know participating youth (Moncloa et al., 2019). Staff describe building relationships with youth and families over the span of 1 year during program implementation. Relationships extended into additional years when youth returned to the program as participants or teen mentors. Staff in one-stop and enrichment organizations describe opportunities for youth and family members to give back to younger children and their communities over time. A staff member from Youth and Community services described that parents and youth helped design holiday decorations throughout the year. Similarly, a staff member from Youth Afterschool shared that parents brought food to end-of-semester celebrations.

Further, staff describe supporting positive Latinx identity development by speaking in Spanish and organizing cultural events such as Day of the Dead and Children's Day. A staff member from Youth Afterschool shared, "We'll speak in Spanish to them and let them know that's very okay and that it shouldn't be something they hide. It's who they are . . . So, they know they're safe here."

Most enrichment organizations partnered with school districts to help students set and achieve goals and overcome academic hurdles, attending to their academic skills and their social and emotional needs. A staff member from Youth Afterschool shared:

So, giving them that power that you choose who you're going to be. It's not who your teachers say or who your parents say you are . . . because I've had conversations with students like, "Well, that's what mom says I am, " or "Well, that's what the teacher says I am. I'm somebody that doesn't listen. I have to throw a fit. I'm always in a bad mood. That's just who I am. "So, they grow to believe that and act that. So, I feel like our job is to let them know that you're not just that and show them kind of their strengths and give them time to show their strengths so they can see that they're more than that and give them that empowerment of being able to change.

These organizations also bridge families and schools to help families navigate educational systems. A staff member at Expanded Learning for All shared, "We offer study groups. . . . We help them apply for scholarships, help them apply for colleges."

In summary, despite shared guiding principles (Moncloa et al., 2019), important variations exist among these three organization types. All organizations sustain Latinx youth participation over time, and differences in their missions and program elements did not reduce their ability to maintain Latinx youth engagement. 


\section{Discussion}

We discuss subtle variations by organization type that reflect mission-related discursive practices, and related orientations to scale and scope. Discursive practices describe how organization types position Latinx youth, and therefore their institutional praxes, in varying ways. Our consideration of scale explores relative emphases on individuals, families, or communities. Differences in scope reflect varied temporal orientations of programming. Table 4 describes organization types and the variations in discourse, scale, and scope.

Table 4. Variations in Discourse, Scale, and Scope of Organization Types

\begin{tabular}{|l|l|l|l|}
\hline \multicolumn{1}{|c|}{ SJYD } & \multicolumn{1}{|c|}{ One-stop } & \multicolumn{1}{|c|}{ Enrichment } \\
\hline Key activities & $\begin{array}{l}\text { Programming } \\
\text { supports youth to } \\
\text { address inequities in } \\
\text { their school or } \\
\text { community }\end{array}$ & $\begin{array}{l}\text { Comprehensive } \\
\text { services for families } \\
\text { and youth } \\
\text { development } \\
\text { programs }\end{array}$ & $\begin{array}{l}\text { Homework tutoring, } \\
\text { activities }\end{array}$ \\
\hline Scale & Youth and community & Youth and families & $\begin{array}{l}\text { Youth in the context } \\
\text { of families }\end{array}$ \\
\hline Scope & $\begin{array}{l}\text { Immediate support } \\
\text { for youth, long-term } \\
\text { for youth and } \\
\text { community }\end{array}$ & $\begin{array}{l}\text { Immediate for } \\
\text { enrichment needs of } \\
\text { youth, long term for } \\
\text { family services }\end{array}$ & Immediate \\
\hline
\end{tabular}

\section{Discursive Variations}

Each organization type positioned quite differently Latinx youth, their roles vis a vis them, participation, and therefore their practices.

Staff in enrichment organizations describe helping youth navigate an education system that does not necessarily serve them well considering their ethnicity, language, socioeconomic status and associated family challenges, or immigration status (Rodriguez \& Morrobel, 2004). Staff offer youth tools and skills to increase their success within existing school systems through homework and tutoring and activities or provide venues outside school in which to learn and have fun (Eccles et al., 2003). Staff also offered children opportunities to develop pride in their heritage, and identity(s), rather than aiming to facilitate systemic change.

Staff in SJYD and one-stop organizations view Latinx youth and family well-being as being under-supported by multiple systems: education, health, legal, transportation, social services, 


\section{Increasing Latinx Youth Engagement}

etc. Staff offer support for navigating these systems based on their experience, and for building resilience in the context of trauma and stress associated with discrimination, economic poverty, and family separation.

Enrichment programs aimed at younger children and managed by one-stop organizations did not give student choices for activities, whereas organizations that engaged adolescents incorporated student choice in activities. However, SJYD programming was fully informed by youth. Most SJYD did not use a set curriculum; youth defined the work by their passions and where they wanted to see change through their actions. One-stop organizations with an advocacy mission also engaged families in decision-making capacity. Youth participation and agency is determined by the context, nature of the relationship between youth and adults, and the organizations' mission.

Beyond recognizing multiple systems that challenge and support Latinx youth and family wellbeing, SJYD ground their activity in analyses that suggest the importance in fostering youth development by building young people's understanding of social disparities associated with race/ethnicity, among other factors, their identities, and capacities as change agents. In this context, SJYD help Latinx youth examine why these challenging conditions exist; consider why they are inequitably distributed across populations and places; and develop knowledge, skills, and networks to build more just and healthy systems and pursue transformative community engagement (Ginwright et al., 2006).

\section{Variations in Scale}

Analyses of scale view varied potential units of attention (e.g., individuals, sub-populations, schools, families, communities, states, nations, and places that link them) as intersecting and non-linear, reflecting organizations' recognition to consider their Latinx participants in relationship to multiple contexts at the same time.

Nonetheless, organization types reflect particular emphases. For example, enrichment organizations oriented themselves around promoting expanded competencies of individuals and their abilities to navigate their school systems. One-stop organizations also focused on individual needs and acted upon the important role of families in the lives of their youth participants. These organizations supported families' abilities to navigate local institutions and contribute to organizational and community needs. In some cases, one-stop organizations' activities intersected with national dynamics, as they sought to support families navigating the U.S. immigration system. 


\section{Increasing Latinx Youth Engagement}

SJYD practices attended to individual youth participants and, to a lesser extent, their families. However, their sphere of attention and engagement tended to focus heavily on broader community, institutional, societal, and transnational contexts-helping young people both to explore and articulate how those contexts shape their own, their family's, and their community's daily experience, and how to be change agents with respect to them.

\section{Variations in Scope}

Academic enrichment and one-stop organizations reflected a tendency to focus on addressing immediate needs-for example, providing academic support in response to underperformance or responding to immediate family crisis situations using a problem-solving approach. Staff built relationships with youth and families over the span of 1 year and did not necessarily aim to sustain relationships with them beyond program participation. Nonetheless, one-stop and enrichment organizations created opportunities for youth participants and family members to give back to younger children and their communities over time.

In light of their objectives to transform people and places to promote more equitable opportunity and outcomes, SJYD viewed their activity on a longer time horizon. They were intentional about fostering sustained youth engagement, continually expanding networks, and creating ladders of opportunity to build upon young people's expanding skills and interest.

\section{Study Limitations}

Limitations of this study include a focus on California, and on interviewees who were predominantly of Mexican descent. Hence, the narratives discussed here may not reflect those of youth professionals from other Latinx subgroups in the United States. This study suggests various youth development organization types and their respective programs sustain Latinx youth participation, and it reveals differences in how these principles are operationalized in practice within each organization type. These practices appear to be consistent within organizational types across varied localities and populations. However, while we collected demographic data on each organization's youth participants, we cannot assess whether there are substantial differences in their backgrounds to suggest a particular "fit" between Latinx youth/families with certain experiences and specific organization types.

\section{Implications}

Several studies pointed to the mediating functions of youth development organizations for families and communities (Gambone \& Connell, 2004; Lerner et al., 2005; Lerner et al., 2011). However, only a few studies bring in contextual understanding of local conditions and how 
these organizations play an important role (Gonzalez, 2010; Hobbs \& Sawer, 2009; Raffaelli et al., 2005). We believe the importance of both context and an organization's guiding philosophies contributes to this scholarship and offers a nuanced understanding of the way different organization types approach and engage with Latinx youth, families, and communities.

In this study, missions and philosophies of organizations shaped the nuanced and varied application of guiding principles for sustaining Latinx youth participation in practice (Erbstein \& Fabionar, 2019). This study suggests organizational context and missions should be part of an ecological understanding of youth development. However, not all youth development organizations have mission-driven strategies. We recommend organizations develop missions to address the needs of the diverse youth and families they serve and align them to their programmatic efforts.

Youth development practitioners would benefit from an understanding of how

- youth-serving organizations can expand their scope by learning from each other,

- to seek out partnerships between youth organizations with limitations and organizations that engage Latinx youth well,

- organizations' overarching conceptual frameworks shape their practices and focus on optimizing these to engage and sustain Latinx youth and families.

For policy makers with a planning perspective, it is useful to think about different organizations meeting different needs while serving the diversity within the Latinx community. For instance, if a community has one type of organization, such as enrichment, it is likely certain needs within the Latinx community-such as empowering older youth to come to terms with and heal from injustices, or basic needs to serve families-might not be met. This presents an opportunity for addressing these needs with Latinx youth, families, and communities.

\section{Acknowledgments}

This project was supported by the University of California, Division of Agriculture and Natural Resources (UC ANR). We acknowledge the significant contribution of Claudia Diaz-Carrasco, Stacy Olagundoye, Claudia Damiani Fontana, Yolva Gil, Russ Hill, and Jose Campos in data collection and analysis.

\section{References}

Cammarota, J., \& Fine, M. (2008). Revolutionizing education: Youth participatory action research in motion. Routledge. 
Journal of Youth Development | http://jyd.pitt.edu/ | Vol. 16 Issue 5 DOI 10.5195/jyd.2021.1084

Increasing Latinx Youth Engagement

Catalano, R. F., Berglund, M. L., Ryan, J. A. M., Lonczak, H. S., \& Hawkins, J. D. (2002). Positive youth development in the United States: Research findings on evaluations of positive youth development programs. Prevention \& Treatment, 5(1), 98-124. (https://doi.org/10.1037/15223736.5.1.515a)

Charmaz, K. (2006). Constructing grounded theory: A practical guide through qualitative analysis. Sage.

Eccles, J. S., Barber, B. L., Stone, M., \& Hunt, J. (2003). Extracurricular activities and adolescent development. Journal of Social Issues, 59(4), 865-889. (https://doi.org/10.1046/j.00224537.2003.00095.x)

Eccles, J., \& Gootman, J. A. (Eds.). (2002). Community programs to promote youth development. National Academy Press.

Eccles, J. S., \& Templeton, J. (2002). Extracurricular and other after-school activities for youth. Review of Research in Education, 26, 113-180.

Erbstein, N. (2013). Engaging underrepresented youth populations in community youth development: Tapping social capital as a critical resource. In M. Calvert, M. Emery, \& S. Kinsey (Eds.), New directions for youth development (pp. 109-124). Wiley Periodicals.

Erbstein, N., \& Fabionar, J. (2019). Supporting youth participation in out-of-school time programs. Afterschool Matters, Spring, 2019. (https://www.niost.org/Afterschool-Matters-Spring2019/supporting-latinx-youth-participation-in-out-of-school-time-programs)

Fox, M., Mediratta, K., Ruglis, J., Stoudt, B., Shah, S., \& Fine, M. (2010). Critical youth engagement: Participatory action research and organizing. In L. Sherrod, J. Torney-Puta, \& C. Flanagan (Eds.), Critical youth engagement: Participatory action research and organizing (pp. 621-649). Wiley.

Futch Ehrlich V. A., Bright, J., DeBate, R., Freeman, C., Harris, P. C., Hirsch, B. J., Johns, S., Markowitz, E., Noam, G. C., Rhodes, Jean, E., \& Somervillle, K. (2017). Universal challenges, specific contexts: Insights from looking within and across different after-school settings. In N. Deutsch (Ed.), After-school programs to promote positive youth development. Springer briefs in psychology. Springer. (https://doi.org/10.1007/978-3-319-59141-4_2)

Gambone, M. A., \& Connell, J. P. (2004). The community action framework for youth development. Prevention Researcher, 11(2), 17-20.

Gandara, P., \& Contreras, F. (2009). The Latino education crisis, the consequences of failed social policies. Harvard University Press.

Ginwright, S., \& Cammarota, J. (2007). Youth activism in the urban community: Learning critical civic praxis within community organizations. International Journal of Qualitative Studies in Education, 20(6), 693-710. 
Journal of Youth Development | http://jyd.pitt.edu/ | Vol. 16 Issue 5 DOI 10.5195/jyd.2021.1084

Increasing Latinx Youth Engagement

Ginwright, S., Noguera, P., \& Cammarota, J. (Eds) (2006). Beyond resistance! Youth activism and community change. Routledge.

Gonzales, L. (2010). Increasing Latino engagement in sustainability and philanthropic efforts of mainstream youth development organizations in the United States [Master's Thesis]. De

Paul University. (https://via.library.depaul.edu/etd/30)

Hobbs, B. B., \& Sawer, B. (2009). Engaging Latino youth in community-based programs: Findings from the first ten years of the Oregon 4-H Latino Outreach Project. Oregon State University.

Hohenemser L. K., \& Marshall, B. D. (2002). Utilizing a youth development framework to establish and maintain a youth advisory committee. Health Promotion Practice, 3(2):155-165. (https://doi.org/10.1177/152483990200300211)

Horton, M., \& Freire, P. (1990). We make the road by walking: Conversations on education and social change. (B. Bell, J. Gaventa, \& J. Peters, Eds.). Temple University Press.

Kirshner, B., Pozzoboni, K., \& Jones, H. (2011). Learning how to manage bias: A case study of youth participatory action research. Applied Developmental Science, 15(3), 140-155. (https://doi.org/10.1080/10888691.2011.587720)

Lerner, R. M., Almerigi, J. B., Theokas, C., \& Lerner, J. V. (2005). Positive youth development, participation in community youth development programs, and community contributions of fifthgrade adolescents: Findings from the first wave of the 4-H study of positive youth development. Journal of Early Adolescence, 25(1), 17-71.

Lerner, R. M., Lerner, J. V, Lewin-Bizan, S., Bowers, E. P., Boyd, M. J., Mueller, M. K., Schmid, K. L., \& Napolitano, C. M. (2011). Positive youth development: Processes, programs, and problematics. Journal of Youth Development, 6(3): 38-62. (https://doi.org/10.5195/jyd.2011.174)

Mahoney, J., Parente, M. E., \& Zigler, E. F. (2009). Afterschool programs in America: Origins, growth, history and politics. Journal of Youth Development, 4(3), 23-42. (https://doi.org/10.5195/jyd.2009.250)

McLaughlin, M., Scott, W. R., Deschenes, S., Hopkins, K., \& Newman, A. (2009). Between movement and establishment: Organizations advocating for youth ( $1^{\text {st }}$ ed.). Stanford University Press. (https://doi.org/10.2307/j.ctvqr1d9z)

Moncloa, F., Erbstein, N., Subramaniam, A., \& Diaz-Carrasco, C. (2019). Guiding principles for reaching and engaging Latinx youth in youth development programs. Journal of Youth Development, 14(2), 46-63 (http://jyd.pitt.edu/ojs/jyd/article/view/19-14-02-FA-03/815) 
Journal of Youth Development | http://jyd.pitt.edu/ | Vol. 16 Issue 5 DOI 10.5195/jyd.2021.1084 Increasing Latinx Youth Engagement

Pew Research Center (2014). Demographic and Economic profiles of Hispanics by state and county, 2014. (https://www. pewresearch.org/hispanic/states/)

Raffaelli, M., Carlo, G., Carranza, M. A., \& Gonzales-Kruger, G. E. (2005). Understanding Latino children and adolescents in the mainstream: Placing culture at the center of developmental models. In R. Larson \& L. Jensen (Eds.), New horizons in developmental research: New directions for child and adolescent development (pp. 23-32). Jossey-Bass.

Rodriguez, M. C., \& Morrobel, D. (2004). A review of Latino youth development research and a call for an asset orientation. Hispanic Journal of Behavioral Sciences, 26(2): 107-127.

Settipani, C.A., Hawke, L.D., Cleverley, K., Chaim, G., Cheung, A., Mehra, K., Rice, M., Szatmari, P., Henderson, J. (2019). Key attributes of integrated community-based youth service hubs for mental health: A scoping review. International Journal of Mental Health Systems, 13(52). (https://doi.org/10.1186/s13033-019-0306-7)

Staples, L. (2004). Roots to power: A manual for grassroots organizing. (2 ${ }^{\text {nd }}$ ed.). Praeger.

Strauss, A., \& Corbin, J. (1998). Basics of qualitative research: Techniques and procedures for developing grounded theory. Sage.

Trask, B. S., Taliaferro J. D., Wilder, M., \& Bey, R. J. (2006) Emerging trends: Holistic, comprehensive family support programs, Journal of Family Social Work, 9(2), 67-93. (https://doi.org/10.1300/J039v09n02_04)

Wheeler, W. (2000). Emerging organizational theory and the youth development organization. Applied Developmental Science, 4(sup1), 47-54. (https://doi.org/10.1207/S1532480XADS04Suppl_6)

Yin, R. K. (2009). Case study research: Design and METHODS ( $4^{\text {th }}$ ed.). Sage.

Zeldin, S., Krauss, S., Collura, J., Lucchesi, M., \& Hadi, S. (2014). Conceptualizing and measuring youthadult partnership in community programs: A cross national study. American Journal of Community Psychology. 54. (https://doi.org/10.1007/s10464-014-9676-9) 